\title{
Formação permanente de professores a partir da trama conceitual freireana
}

Helga Porto Miranda ${ }^{1}$, Lormina Barreto Neta ${ }^{2}$

\section{Resumo}

O presente texto visa apresentar reflexões a partir da trama conceitual freireana que foi construída a partir das ponderações realizadas na Cátedra Paulo Freire, na Pontifícia Católica de São Paulo, da qual elegemos para essa análise a categoria: Formação Permanente de professores, a partir da leitura e reflexão da obra de Paulo Freire: Política e Educação: Ensaios (2001), A importância do ato de ler: em três artigos que se completam (1989), Professora sim; tia, não: Cartas a quem ousa ensinar (2017), Medo e ousadia: cotidiano do professor (1986) e $O$ caminho se faz caminhando: conversas sobre educação e mudança social (2011). Essa reflexão contribuiu para pensar a formação dos professores considerando a possibilidade de desenvolver a conscientização, criticidade e humanização do profissional, assim como orienta o currículo, as práticas pedagógicas e os processos de ensino e aprendizagem. Para alcançarmos esse objetivo, é necessário haver diálogo, participação e autonomia dos professores.

\section{Palavras-chave}

Formação Permanente. Leitura de mundo. Trama conceitual freireana.

\footnotetext{
${ }^{1}$ Doutora em Educação e Currículo pela Pontifícia Universidade Católica de Campinas, São Paulo, Brasil; professora efetiva da Universidade do Estado da Bahia, Campus Jacobina, Brasil. E-mail: helgaportopc@gmail.com.

${ }^{2}$ Doutora em Educação (Currículo) pela Pontifícia Universidade Católica de Campinas, São Paulo, Brasil; professora efetiva da Universidade do Estado da Bahia, Campus Irecê, Brasil. E-mail: lobaneta@ hotmail.com.
} 


\title{
Permanent training of teachers from the freirean conceptual plot
}

Helga Porto Miranda ${ }^{3}$, Lormina Barreto Neta ${ }^{4}$

\begin{abstract}
This text aims to present reflections on the permanent formation of the professional who works in basic education, based on the Freirean conceptual framework, built from the considerations made at the meetings of the Paulo Freire Chair, at the Pontifical Catholic University of São Paulo (PUC/SP). We chose the following category for this analysis: Permanent Teacher Education, from the reading and reflection of Paulo Freire's works: Politics and Education: Essays (2001), The importance of the act of reading: in three articles that are completed (1989), Teacher yes; auntie, no: Letters to those who dare to teach (2017), Fear and daring: the teacher's daily life (1986) and The way we walk: conversations about education and social change (2011). We deepened our readings in Freire, looking for the concepts and foundations that help us thinking about the permanent formation of teachers. We identified the need to develop awareness, criticality and humanization of the professional who works in education, as well as guiding the curriculum, pedagogical practices and teaching and learning processes. In this formative path, it is necessary to develop dialogue, participation and autonomy for teachers
\end{abstract}

\section{Keywords}

Ongoing formation. World reading. Freirean conceptual plot.

\footnotetext{
${ }^{3} \mathrm{PhD}$ in Education and Curriculum, Pontifical Catholic University of Campinas, State of São Paulo, Brazil; professor at the State University of Bahia, Campus Jacobina, State of Bahia, Brazil. E-mail: helgaportopc@gmail.com.

${ }^{4} \mathrm{PhD}$ in Education (Curriculum) by the Pontifical Catholic University of Campinas, State of São Paulo, Brazil; professor at the State University of Bahia, Campus Irecê, State of Bahia, Brazil. E-mail: lobaneta@hotmail.com.
} 


\section{Introdução}

Este artigo visa apresentar reflexões a partir da trama conceitual realizada na Cátedra Paulo Freire da Pontifícia Universidade Católica de São Paulo (PUC/SP), criada desde 1998, vinculada ao Programa de Pós-Graduação em Educação: Currículo. A cadeira é coordenada pela professora doutora Ana Maria Saul, também responsável pelo Grupo de Pesquisa: O pensamento de Paulo Freire na educação brasileira. O grupo constitui uma rede de pesquisadores de diferentes universidades, vinculados a Programas de Pós-graduação em Educação, que pesquisam o legado de Paulo Freire e sua reinvenção em sistemas de educação no Brasil.

A Cátedra caracteriza-se por ser um espaço de aprendizagem colaborativa e coletiva em que se tece a análise da realidade econômica, social, cultural e educacional na conjuntura atual. Para Saul (2014, p. 39-40), “A Cátedra Paulo Freire vem sendo construída como um espaço privilegiado de estudos e pesquisas sobre a obra de Paulo Freire, focalizando suas repercussões na educação e sua potencialidade de fecundar novos pensamentos e novas práticas".

Aprendemos, nesse lócus, a reinventar o legado freireano, a partir da leitura crítica de sua obra, sem descaracterizar o pensamento e proposta de Freire, atentos em discutir Paulo Freire, segundo os desafios do mundo atual, construindo e sistematizando uma práxis coerente com os princípios da teoria cunhada pelo autor.

$\mathrm{Na}$ Cátedra, realizamos estudos de uma pedagogia freireana praticada, em que se constrói o conhecimento de forma coletiva, a projetos de pesquisa dos mestrandos e doutorandos que se aventuram na construção da trama do quefazer da educação nos dias atuais, na perspectiva de fazer com o outro, articulando o pensar a educação em sintonia com o que acontece no cotidiano do trabalho do professor a partir da tematização da prática articulada com a curiosidade epistemológica esperançosa.

Para Saul (2014, p. 41), a Cátedra se constitui: "um lócus no qual, ao mesmo tempo, "se leva" e "se deixa" conhecimento produzido, para construções posteriores. Para isso, tem sido necessário registrar o que se faz, sistematizar e divulgar as experiências e produções".

É nesse contexto que apresentamos os estudos relativos à formação permanente de professores em Freire, a partir de algumas categorias consideradas imprescindíveis para a análise crítica da formação de professores e seu processo permanente de construção de conhecimentos e saberes concernentes a sua prática eminentemente ética, estética e política. 
Como nos afirma Freire (1991), não é possível mudar a escola sem se centrar na formação permanente do professor, que, pensando a sua prática, possa descobrir embutida na sua prática a teoria que sabia ou não sabia.

Na Cátedra Paulo Freire, buscamos realizar atividades e ações nos contextos de ensino e de pesquisa, com o objetivo de subsidiar seus pesquisadores (mestrandos e doutorandos) no desenvolvimento das suas pesquisas, bem como em sua ação docente, no contexto de atuação profissional, por meio de análise e discussão de referenciais do pensamento de Paulo Freire na atualidade. Como nos afirma Saul (2014, p. 41), na Cátedra, as aprendizagens nascem:

No contexto de ensino e aprendizagem, a prática é trazida para a sala de aula por meio das intencionalidades de pesquisa de alunos, de representações da realidade e do saber de experiência feita dos educandos/pesquisadores. Dessa forma, ensino e pesquisa se interpenetram, mediados pela teoria e prática.

Nessa perspectiva de que ensino e pesquisa transcorrem de forma inseparáveis e são intermediados pela teoria e prática, como algo interrelacionados e interdependentes, a Cátedra Paulo Freire integra os componentes curriculares optativos do curso de Doutorado em Educação: currículo oferecido com carga horária de 60 horas/aula. Seus encontros são realizados semanalmente com a duração de três horas/aula. Para isso, os mestrandos e doutorandos devem realizar sua matrícula na secretaria acadêmica.

Os cursos da Cátedra são constituídos por mestrandos, doutorandos e pós-doutorandos, vinculados aos Programas de Pós-Graduação, como: Psicologia e Educação, Educação: Currículo e do Mestrado profissional Formação: Formadores, assim como professores convidados vinculados a grupos de pesquisa de diversas áreas como: Educação, Psicologia, Direito e Serviço Social, o que constitui um caráter intercultural e interdisciplinar. Esse grupo é composto por 25 pesquisadores.

As temáticas abordadas e aprofundadas no âmbito da Cátedra surgem a partir dos projetos de pesquisa dos mestrandos e doutorandos, construídos de forma coletiva e colaborativa, respeitando as categorias freireanas que cada projeto de pesquisa pretenda aprofundar. A partir da temática e objeto de estudo dos pesquisadores é que a trama freireana é constituída juntamente.

Os alunos do mestrado ou doutorado dos programas de Pós-Graduação da PUC-SP, que têm a professora Ana Maria Saul como orientadora, participam das atividades e encontros 
desenvolvidos pela Cátedra durante todo o percurso da sua formação acadêmica, visto que essas atividades são vinculadas às pesquisas desenvolvidas no Grupo de Pesquisa Paulo Freire na atualidade brasileira.

O recurso teórico e metodológico desenvolvido nesse espaço baseia-se na construção da trama conceitual freireana, considerando múltiplos itinerários de estudo e pesquisa. Caracteriza-se por analisar um fenômeno educativo que toma como referencial a teoria de Paulo Freire num modelo ilustrativo, em que se elegem categorias de estudo e suas interconexões, colocando- $\theta$ no centro o conceito principal, que nesse caso é "Formação Permanente". Segundo Saul e Saul (2018, p. 1.145):

A construção da trama conceitual freireana, um recurso teóricometodológico para o ensino e a pesquisa, insere-se nos campos da teoria e do desenvolvimento curricular e pode subsidiar discussões e práticas curriculares em todas as modalidades e níveis de ensino.

A trama conceitual é uma ação criadora do estudioso e pesquisador que empresta seu olhar e compreensão às categorias escolhidas e às relações estabelecidas entre elas a partir da obra freireana. As setas utilizadas na ilustração têm a função de dinamizar a direção e a relação dos conceitos entre si, podendo uma mesma trama ter interligações e direções diferenciadas, conforme a análise crítica e rigorosa realizada pelo autor que construiu a trama. Saul e Saul (2018, p. 1.149), argumentam que:

A construção de uma trama é uma ação criadora que permite novas sínteses críticas sobre aspectos da teoria e da prática, por meio do entrelaçamento metódico de conceitos e da problematização de suas interrelações. Daí o seu caráter epistemológico, caracterizado pelo rigor teórico de processos e produção de conhecimento, sob uma nova lógica. Não é uma produção estática, necessitando ser revisitada e recriada de acordo com a problemática que se quer explicitar/pesquisar e o momento histórico em que se vive. A trama pode subsidiar denúncia de situações que apresentam desigualdades de diferentes ordens, nos contextos analisados e de obstáculos para a realização de trabalhos educativos humanizadores. Pode ainda trazer contribuições para anunciar a superação dessas situações e empecilhos.

Nessa perspectiva, utilizamos a trama conceitual freireana como recurso teórico e metodológico de pesquisa e ensino no âmbito do grupo de pesquisa e Cátedra por nos possibilitar as interconexões entre a categoria elencada "Formação Permanente" e a obra freireana relacionada à análise dos achados das pesquisas, seja ela bibliográfica ou de campo, 
ou mesmo para sistematizar o conteúdo de um estudo em contexto, seminário e outras situações de ensino e pesquisa. Seguimos o pensamento freireano, no que diz respeito:

Estudar é um que-fazer exigente em cujo processo se dá uma sucessão de dor, de prazer, de sensação de vitórias, de derrotas, de dúvidas e de alegria. Mas estudar, por isso mesmo implica a formação de uma disciplina rigorosa que forjamos em nós mesmos, em nosso corpo consciente [...]. Quanto mais assumimos esta disciplina tanto mais nos fortalecemos para superar a ela e, portanto, á capacidade de estudar eficazmente (FREIRE, 1993, p. 102).

Desse modo, buscamos pautar nossas discussões a partir de um dos conceitos mais populares da obra de Freire que é "a leitura do mundo e a leitura da palavra", enfatizando a importância da leitura da realidade educacional presente no contexto do trabalho dos professores que se formam permanentemente no cotidiano da atividade docente das escolas presentes nas comunidades e bairros desse nosso imenso país.

Com vistas a compreender questões referentes à formação permanente dos professores, tendo o tear nas mãos (a Cátedra), vamos tecendo aprendizagens, pensando no coletivo, para que os pesquisadores presentes possam debater, analisar, refletir sobre essas questões a partir do espaço que ocupam, pesquisar, deixar e levar contribuições construídas nesse espaço vivo, pulsante e esperançoso de uma sociedade menos desigual e mais justa.

Apresentamos a formação permanente do professor, a partir da leitura de mundo em Freire e, posteriormente, analisaremos a trama conceitual tecida com a intencionalidade de pensarmos a formação permanente na perspectiva freireana e sua contribuição para mudar a cara da educação nas escolas.

\section{A formação permanente do professor, a partir da leitura de mundo em Freire}

No contexto atual da educação, muito se tem debatido a necessidade da formação continuada dos profissionais da educação, ou, como nos afirmava Freire (1996), a necessidade da educação permanente. É preciso anunciar mudanças que possam propiciar atitudes de luta e enfrentamento pela via da formação permanente, que desenvolvam nesses profissionais da educação uma atitude crítica, reflexiva, emancipadora. Para que se possa pensar na mudança gradativa para uma educação mais humana e democrática no interior das escolas, a formação permanente constitui-se um caminho possível.

Para Freire (1989), aprender a ler não é aprender a dizer a palavra, mas vivê-la, compreendê-la pela sua passagem no mundo. A palavra existe para se exercitar a denúncia das situações opressoras e o anúncio da emancipação e humanização. Nesse sentido, Freire criou 
o conceito da palavração, que significa a palavra sendo dita para provocar mudanças, transformações do sujeito em si ao sujeito para si, ou seja, aquele ser ontológico que por ser inacabado pode transformar a si e ao mundo que o cerca para poder ser mais (FREIRE, 1993).

Para o autor, nossa existência não pode ser muda, não se pode silenciar a palavra do sujeito social, do educando, do educador, da pessoa em qualquer circunstância. Nesse sentido, também se dá a do-discência, conceito criado por Paulo Freire para se referir a uma desejável postura de eterno aprendiz por parte do educador, ou seja, a junção da palavra docente + discente $=$ dodiscente $=$ educador, sempre disposto a aprender com o que faz e com o próprio aprendiz. Para Freire (1998, p. 31),

Significa a inseparabilidade do ensinar e do aprender. Ensinar, aprender e pesquisar lidam com dois momentos do ciclo gnosiológico: o em que se ensina e se aprende o conhecimento já existente e o que se trabalha a produção do conhecimento ainda não existente. Nessa perspectiva a dodiscência e a pesquisa indicotomisáveis, são assim práticas requeridas por esses momentos gnosiológicos.

Tomando como orientação o pensamento freireano, a formação do professor não pode ser apenas baseada em conhecimentos transmitidos, mas na construção de conhecimentos por meio do ensinar e do aprender, da troca com o outro, em ambientes colaborativos, nos quais professores e alunos aprendem e ensinam, trocam experiências, constroem conhecimentos e, portanto, ambos são aprendizes.

Ao construirmos conhecimentos, ao aprender, ao ensinar, provocamos mudanças, transformamos a nós mesmos e transformamos o mundo. No entanto, para transformar o mundo, começamos pelo espaço em que estamos e atuamos, no espaço da ação/reflexão/ação.

É na leitura da palavra e do mundo, no espaço da ação docente, que damos o pontapé inicial, de transformação do mundo, da palavração e da do-discência, tão debatida na obra freireana. Desse modo, pensamos a formação humana e profissional, emancipatória, ética, comprometida e compromissada com o sujeito social e político, uma formação que contribui para a construção da práxis.

Para Freire (1996), a prática só se viabiliza com uma formação docente que seja coerente com seus pressupostos, e para exercer a docência, é necessário:

Rigorosidade metódica, pesquisa, respeito aos saberes dos educandos, criticidade, ética e estética, corporificar as palavras pelo exemplo, assumir riscos, aceitar o novo, rejeitar qualquer forma de discriminação, reflexão crítica sobre a prática, reconhecimento e assunção da identidade cultural, ter 
consciência do inacabamento, reconhecer-se como um ser condicionado, respeitar a autonomia do ser educando, bom senso, humildade, tolerância, convicção de que mudar é possível, curiosidade, competência profissional. (FREIRE, 1996, p. 147-149).

A formação desse profissional que atua na educação, seja inicial ou permanente, deve considerar o exercício da docência, da sua ação pedagógica, deve atentar para concepções educacionais freireanas, que se traduzam na construção da práxis educativa crítica. Trabalhar os princípios para uma educação libertadora, emancipadora, que são aspectos indissociáveis do fenômeno educativo. Ter clareza sobre os pressupostos da educação emancipadora se faz indispensável para compreendemos a formação permanente dos professores.

Nessa perspectiva, foge-se do saber instrumental que desestimula a inventividade do sujeito e a busca por Ser Mais, direito de todos. Para que isso se viabilize, necessário se faz ouvir a palavra dos professores sujeitos da formação, comunidade escolar em que se trabalha para que a palavra, dita e ouvida em seu sentido possa transformar-se em palavração, no dizer de Freire (1993) ação para a prática que liberta, uma vez que é ação cultural que transforma o quefazer no cotidiano formativo.

Compreendemos que a proposta pedagógica de Freire se alicerça sobre a base da ação reflexiva e dialógica e se articula como possibilidade de transformação da pessoa e da sociedade. "Educação que, desvestida da roupagem alienada e alienante, seja uma força de mudança e de libertação" (FREIRE, 2007, p. 44). A partir dessa concepção construímos a trama freireana, pensando a formação permanente de professores.

\section{Trama conceitual "Formação Permanente"}

A formação do profissional da educação tem provocado muitos debates, discussões e pesquisas, tendo como foco a prática docente e seus contextos de atuação. Realizamos a trama curricular elencando os pontos centrais do pensamento de Freire no enfoque da formação permanente de professores, que orienta a prática pedagógica e sua relação com o processo de ensino e aprendizagem. Nesse sentido, consideramos que requer diálogo, orienta o currículo que, por sua vez, requer a formação que objetiva a humanização/inclusão e a conscientização/criticidade.

Na sequência, apresentaremos as relações estabelecidas entre a Formação Permanente e as categorias freireanas elencadas na trama conceitual em sentido horário, por considerarmos essa organização mais coerente para mostrar as conexões entre os conceitos. 
Figura 1 - Trama conceitual centrada na Formação Permanente

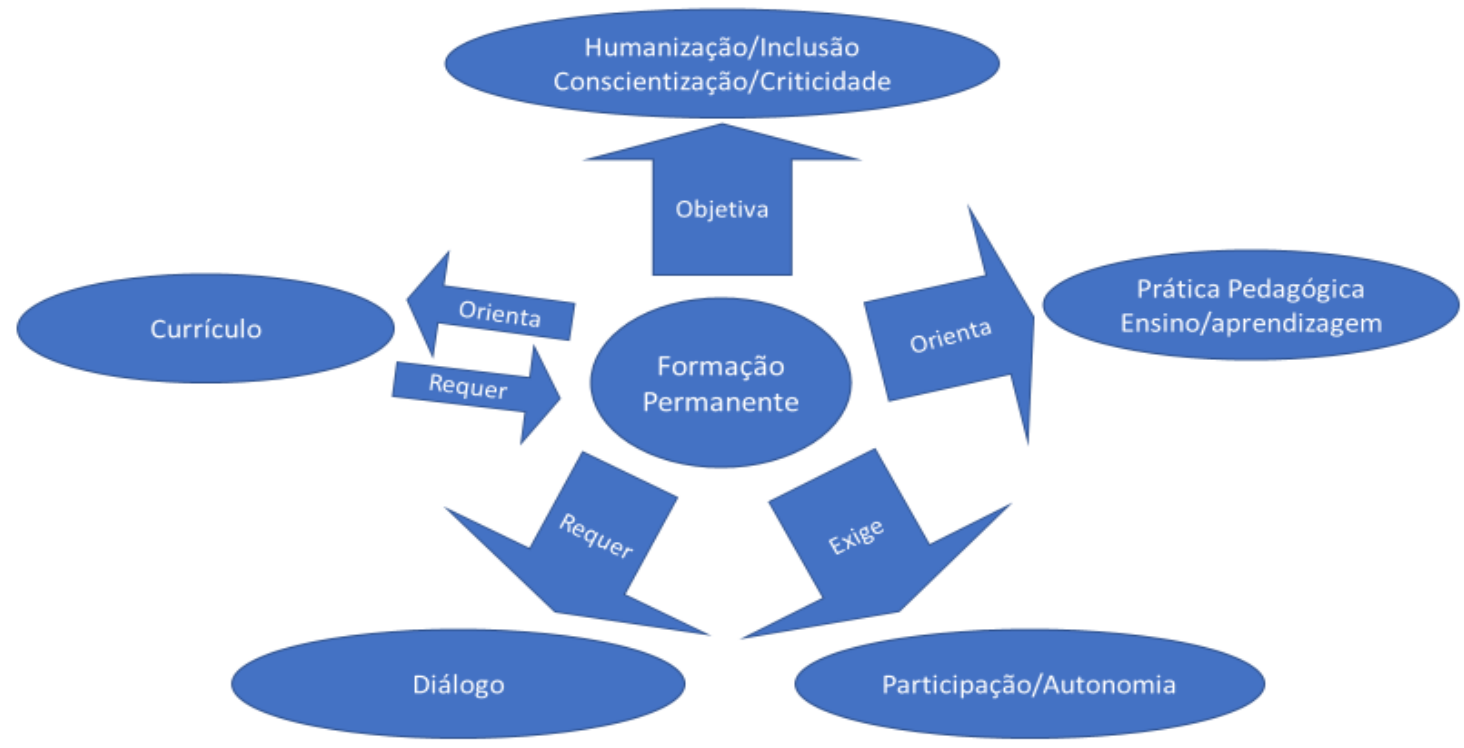

Fonte: Trama construída pelos pesquisadores da Cátedra Paulo Freire - PUC/SP (2019).

Iniciamos a leitura da nossa trama pela "Formação Permanente que orienta a prática pedagógica a partir das categorias elencadas": Humanização/Inclusão e Conscientização/Criticidade, Prática Pedagógica e Ensino/Aprendizagem, Participação/Autonomia, Diálogo e Currículo.

$\mathrm{Na}$ pedagogia freireana, a prática pedagógica dá-se em uma relação na qual o processo de ensinar faz parte do processo de aprender e o processo de apender é parte do processo de ensinar. Nessa relação, dialógica e dialética, o conhecimento se constrói. Para Freire (1993), o conhecer exige a relação dialógica entre sujeitos e o objeto do conhecimento e, nessa relação, é por meio da observância do outro na interação estabelecida na prática pedagógica e educativa que o conhecimento se constrói, desconstrói e reconstrói.

O processo de ensino não se dá a partir apenas do "eu", mas a partir do "outro", pois existe um conhecimento que já foi aprendido e necessita do outro para ser ensinado, e nesse fazer docente o ensinante aprende também a refletir sobre a sua prática de ensinar ( $d o$ discência). É nesse sentido que a formação permanente orienta a prática pedagógica, posto que "a formação permanente se funda na prática de analisar a prática" (FREIRE, 2001, p. 37), ou seja, ao analisar a prática, há fundamentamos para transformá-la; como professores estamos sempre a nos formar, a aprender, a construir conhecimentos que fundamentam nossa prática e nossa práxis.

Ao ensinar, aprendemos, ao aprender, repensamos, revemos e ressignificamos nossas práticas. Freire enfatiza em seu livro Professora sim, tia não, que: 
$\mathrm{O}$ aprendizado do ensinante ao ensinar se verifica na medida em que o ensinante, humilde, aberto, se ache permanentemente disponível a repensar o pensado, rever-se em suas posições; em que procura envolver-se com a curiosidade dos alunos e os diferentes caminhos e veredas que ela os faz percorrer. (FREIRE, 1993, p. 55).

Nessa perspectiva, a natureza da prática educativa, e sua necessária diretividade, que deve ser assumida, não é neutra, havendo necessidade de se ter objetivos claros ao se pensar nos conteúdos e no modo de trabalhá-los posto que, na perspectiva freireana, "o necessário ensino dos conteúdos está sempre associado a uma leitura crítica da realidade" (FREIRE, 1991, p. 29), uma vez que o contexto escolar está eivado dos conflitos e tensões sociais que adentram a escola e devem ser levados em consideração numa prática pedagógica que se diz libertária e transformadora, assim na construção de uma práxis emancipatória.

Para uma educação emancipadora, Freire (1991) alerta para o compromisso político de luta contra opressão e dominação. A educação para a emancipação se configura como libertadora, amorosa, humanizante e politicamente engajada com a causa dos oprimidos.

Assim, se faz necessária uma formação que possibilite a "reflexão crítica sobre a prática", que proporcione ao professor voltar seu olhar criticamente sobre sua ação pedagógica, com capacidade para perceber acertos e desacertos, compreendendo que é necessário transcender do ativismo prático para a construção da práxis pedagógica, e possibilitar a concretização de mudanças no seu pensar e agir docentes. "Na formação permanente dos professores, o momento fundamental é o da reflexão crítica sobre a prática. É pensando criticamente a prática de hoje ou de ontem que se pode melhorar a próxima prática" (FREIRE, 1996, p. 44).

A formação permanente exige a participação ativa nos processos de decisão no cotidiano social e escolar dos sujeitos envolvidos no processo educativo: professores, gestores, alunos. Só pela participação implicada com a transformação da realidade educacional e social, é que se pode favorecer o engajamento dos sujeitos sociais e curriculares no processo de aprendizagem da democracia. Só a participação efetiva poderá favorecer as comunidades escolares a construir a autonomia de pensar criticamente os encaminhamentos necessários a uma realidade específica e contextualizada.

Nesse sentido, Freire aponta que é impossível fazer uma educação democrática, em favor da autonomia dos aprendentes pelo poder autoritário e hierarquizado de uma escola que burocratiza inclusive as relações estabelecidas no contexto das aprendizagens. Como nos 
afirma, "o caminho se faz caminhando" (FREIRE; HORTON, 2011, p. 38) e só se aprende a participar, participando.

Em sua obra Pedagogia da Autonomia, Freire (1996) coloca a autonomia como o direito à curiosidade, à inquietude, a à não acomodação inerente do sujeito inacabado. Tratase de libertar o ser humano do determinismo inculcado pela cultura neoliberal. Homem e mulher são seres de possibilidades, ou seja, seres de um inédito viável, posto que inconclusos e conscientes dessa inconclusão. Para o autor,

A educação é permanente não porque certa linha ideológica ou certa posição política ou certo interesse econômico o exijam. A educação é permanente na razão, de um lado, da finitude do ser humano, de outro, da consciência que ele tem de sua finitude. Mais ainda, pelo fato de, ao longo da história, ter incorporado à sua natureza não apenas saber que vivia, mas saber que sabia e, assim, saber que podia saber mais. A educação e a formação permanente se fundam aí (FREIRE, 2001, p. 12).

Segundo Freire, não construímos a autonomia de forma imediata, e sim a partir da prática, com a experiência, com as decisões tomadas, a autonomia é um amadurecimento para si, é um processo, é um vir a ser. Para cada decisão, uma responsabilidade a ser assumida, a construção da autonomia se constitui uma experiência respeitosa de liberdade.

Outro aspecto analisado foi que a formação requer diálogo, e ele não se dá no vazio, no senso comum apenas. Para dialogar, é necessário um objeto do conhecimento, intermediando a interação entre os sujeitos com o objetivo de produzir conhecimento. $\mathrm{O}$ diálogo exige uma metodologia e uma sistematização do que se constrói nessa interação, na união entre as pessoas, em busca do comum, sendo que uma das condições para sua existência é a humildade em reconhecer os diferentes tipos de conhecimento, o respeito ao conhecimento do outro, respeito ao pensar diferente, a discordar, a ser e pensar na individualidade e no coletivo. "O diálogo é a fonte geradora de reflexão, e o encontro com o outro é a primeira condição da instauração do diálogo em sala de aula" (CARVALHO, 2005, p. 69).

A relação dialógica se estabelece entre educadores e educandos na esperança de uma educação libertadora, tendo como alvo a libertação, a emancipação humana. Essa perspectiva torna a relação professor/aluno, uma relação de cumplicidade, de respeito, de afeto, tornandoa um ato amoroso.

Destarte, a formação permanente na perspectiva dialógica requer rigor responsável, pois exige que o aprendiz participe da sua própria formação. É preciso disciplina para aprender, para organizar a leitura da realidade assumindo a sua responsabilidade intelectual, 
forjando assim o silenciamento da palavra em momentos importantes de participação na luta por uma sociedade mais humana e justa (FREIRE, 1987). Portanto, o diálogo é tomado na perspectiva freireana como fonte de reflexão, de ação, de criatividade, e de compartilhamento de vivências e experiências, condição de construção de conhecimento crítico emancipatório.

Por meio da trama, identificamos que a formação permanente também orienta o currículo. Freire acreditava que o currículo tem sentido quando construído em diálogo com os sujeitos curriculares. Saul e Saul (2018, p. 129), corroborando Freire, acrescentam “articulando-se a sua dimensão ético-política, metodológico-investigativa e epistemológicopedagógica para responder as questões: Currículo para quê? Currículo pra quem? Currículo a favor de quem?". O currículo fortalece a democracia; possibilita o acesso a informações, a construção de saberes e a valorização dos conhecimentos cotidianos.

Para Freire, não existe neutralidade em educação. Nessa perspectiva, o currículo, abarca a política, a teoria e as práticas educacionais, o currículo é um instrumento de justiça social. Portanto, uma educação que se diz crítica-transformadora não pensa a formação dos professores sem antes pensar o que queremos na educação, que sujeito formar e que concepção de educação temos. Como nos afirmam Saul e Saul (2018, p. 1.149), "sobre o horizonte que queremos para formar crianças, jovens e em consequência, que opções faremos quanto a valores a assumir, conhecimentos a serem selecionados, procedimentos de ensino e aprendizagem, formação de educadores e avaliação".

Considerando-se as questões supracitadas, a formação permanente discute as necessidades apontadas pelos profissionais da educação no sentido de uma orientação do quefazer educativo na gestão do currículo pensado, que por ser dinâmico, requer sempre aproximações sucessivas do currículo desejado a partir das ações pensadas no processo formativo.

Para Freire (1993), a formação deve ser permanente pela condição ontológica do ser humano. Somos seres inacabados e conscientes dessa inconclusão, por isso sempre em busca de saber mais. Por isso, a formação, segundo Saul e Saul (2018, p. 169), "trata-se de uma prática social que valoriza e respeita os educadores como sujeitos de conhecimento, capazes de avaliar criticamente as suas práticas e participar ativamente das decisões sobre seus percursos".

A formação do professor objetiva a humanização/inclusão, conscientização/criticidade. Freire foi reconhecido por defender uma educação fundamentada em uma pedagogia humanizadora e libertadora, que desenvolva uma consciência crítica, numa 
relação dialógica e dialética, na qual alunos e professores são sujeitos que se educam mutuamente. No entanto, a humanização só se torna possível na relação com o mundo e com o outro. Freire afirma que a humanização é justamente a capacidade de esperançar, de ser mais e de perceber a possibilidade de mudar as situações-limites na constante busca de autofazer-se no mundo. É, portanto, por essa percepção que o autor nos afirma que:

É na inconclusão do ser, que se sabe como tal que se funda a educação como processo permanente. Mulheres e homens se tornaram educáveis na medida em que se reconhecem inacabados. Não foi a educação que fez homens e mulheres educáveis, mas a consciência de sua inconclusão é que gerou a educabilidade. (FREIRE, 1996, p. 64).

É no contato com a contradição constante nessas relações de humanização e desumanização que se constrói o homem histórico-cultural. Cuidar desse fazer-se homem e mulher é uma das preocupações da pedagogia freireana, em que a humanização e a desumanização-devem ser consideradas como parte da história, num contexto real, concreto e objetivo a ser visto como possibilidade de homens e mulheres, seres inconclusos e conscientes de sua inconclusão, se humanizarem.

Para Ecco e Nagaro (2015, p. 3.526),

Educação e humanização são termos indicotomizáveis, pois educar, em síntese, objetiva formar e "trans-formar" seres humanos, valorizando processos de mudança dos sujeitos, atualizando suas potencialidades, tornando-os humanos. Ademais, concebemos o ato pedagógico como um ato de educar; e o trabalho do educador efetiva-se com e entre seres humanos. E, nesse sentido, compreendemos que uma educação autêntica promove a dignidade das pessoas, esperançosa de que vivam humanamente, isto é, que sejam capazes de fazerem-se, construírem-se, inventarem-se, desenvolverem-se, pois não nascemos prontos, acabados, satisfeitos. E essa condição, do homem e da mulher de nascerem não feitos, exige que, ambos, aprendam a ser gente, a constituírem-se humanos.

Vivemos em complexo processo de construção e desconstrução de saberes e fazeres pedagógicos. No contexto de atuação e ação educacional, estamos nos transformando sempre. Tudo muda, tudo se transforma, a relação entre professores e alunos constrói-se nas relações humanas, afetivas, amorosas, em busca da dignidade humana. A vida é uma eterno refazer.

Outro aspecto abordado é a inclusão, que se constitui um elemento fundamental para aqueles que trabalham com a pedagogia humanista freireana, posto que se volta para os excluídos, os oprimidos, portanto uma pedagogia que acolhe, inclui, constrói com e para o excluído. Para que esse "fazer com” se efetive, necessário se faz a conscientização de que se é 
excluído ao analisar criticamente a situação de exclusão em que se encontra e se engajar na luta por libertar-se da exclusão. Para Freire (1993, p. 53) "esta superação exige a inserção crítica dos oprimidos na realidade opressora, com que, objetivando-a, simultaneamente atuarem sobre ela”. É nessa relação dialética que o sujeito constrói a si mesmo e transforma a realidade, transformando a sua ação no mundo numa práxis transformadora.

A transformação da educação não será construída na perspectiva apenas da teorização acadêmica, do academicismo, nem tampouco pelo ativismo irrefletido da prática cotidiana, a transformação da educação se dará, e Paulo Freire incansavelmente insistia em toda a sua obra, pela práxis: pela ação refletida e reflexionada na teoria. Mas não é qualquer práxis, é a práxis comprometida eticamente com os oprimidos da sociedade.

É a transformação por meio da práxis-que encontra seu chão fértil no espaço, tempo e lugar da educação, da escola, principalmente do chão da escola pública da educação básica. Para a escola tornar-se o lugar da viabilização da educação emancipadora, tão sonhada por Freire, carece criar um olhar para as concepções e práticas pedagógicas, é preciso transformar esses espaços pedagógicos e os cotidianos do exercício educativo.

\section{Considerações finais}

A incursão pelas obras de Freire possibilitou uma revisitação às leituras feitas em outros momentos formativos, em outros contextos históricos, o que nos assegura dizer que a leveza que o autor empresta aos seus escritos possibilita uma leitura fluida e, muitas vezes, flutuante, dando a impressão de facilidade por ser tão coerente e profundo na produção da palavra escrita e dita com sentido. Porém, percebemos que revisitá-lo para uma escrita autoral não se constitui um processo construtivo fácil, pois é de muita responsabilidade compreender na prática o que foi construído por Freire, e reinventá-lo na atualidade.

Porém, é importante, nos dias atuais, esse exercício de humanizar-se, até porque segundo a pedagogia humanista freireana, somos vocacionados à humanização e ela não se dá sem a percepção da nossa natureza do vir a ser, o devir. $O$ vir a ser um melhor escritor da realidade humanamente construída.

No contexto da educação, identificamos a importância da formação permanente para professores, gestores e para a comunidade escolar. A educação não é estática, pois encontra-se em processo de mudanças, transformações e, por que não dizer, em evolução. 
Ao fazer a leitura da obra de Freire, fomos elencando a formação permanente a partir de categorias freireanas e identificamos que ela objetiva a humanização, conscientização e criticidade.

Para que a formação aconteça, exige-se diálogo entre os pares, estimulando a participação e construção da autonomia no espaço escolar e não escolar.

O processo contínuo de formação orienta também a construção de um currículo, que tenha como prioridade o sujeito social que está formando, assim como os processos de ensino e de aprendizagem. A importância da formação, que contribua para a reflexão e reconstrução das práticas e do quefazer docente. É o momento em que os professores podem pensar criticamente sobre suas práticas, sobre o que fazem e sobre sua ação docente.

O investimento em formação contribui para a construção da práxis educativa, pedagógica, e que ela subsidie e instrumentalize o professor para que ele possa criar e recriar a sua prática, a partir das reflexões sobre seu cotidiano docente.

Compreendemos como Freire continua vivo em nossas utopias e realidade concreta, não só no contexto da educação, mas também na concepção de vida e emancipação humana de cada sujeito social. A formação permanente de professores já avançou muito, mas ainda carece superar os muitos desafios que são postos na realidade do cotidiano de cada e de todas as escolas. Somos e vivemos na incompletude, na busca permanente de nos constituirmos e nos construirmos profissionais da educação, lutando por um mundo melhor, mais humano, digno e solidário. Um mundo de sujeitos livres, participantes, autônomos, emancipados. Seres humanos participantes da nossa história.

\section{Referências}

CARVALHO, A. L. Os caminhos perversos da educação: a luta pela apropriação do conhecimento no cotidiano da sala de aula. Cuiabá: EDUFMT, 2005.

ECCO, I.; NAGARO, A. A educação em Paulo Freire como processo de humanização. In: CONGRESSO NACIONAL DE EDUCAÇÃO - EDUCERE, 12., 2015. Disponível em: https://educere.bruc.com.br/arquivo/pdf2015/18184_7792.pdf. Acesso em: 15 maio 2020.

FREIRE, P. A importância do ato de ler: em três artigos que se completam. São Paulo: Autores Associados: Cortez, 1989.

FREIRE, P. Educação como prática da liberdade. 30. ed. Rio de Janeiro: Paz e Terra, 2007.

FREIRE, P. Educação na cidade. São Paulo: Cortez, 1991. 
FREIRE, P. Pedagogia da autonomia: saberes necessários a prática educativa. São Paulo: Paz e Terra, 1996.

FREIRE, P. Pedagogia do oprimido. 17. ed. São Paulo: Paz e Terra, 1987.

FREIRE, P. Política e educação: ensaios. 5. ed. São Paulo: Cortez, 2001.

FREIRE, P. Professora sim; tia, não: cartas a quem ousa ensinar. São Paulo: Paz e Terra, 1993.

FREIRE, P.; HORTON, M. O caminho se faz caminhando: conversas sobre educação e mudança social. 6. ed. Petrópolis-RJ: Vozes, 2011.

FREIRE, P.; SHOR, I. Medo e ousadia: cotidiano do professor. Rio de Janeiro: Paz e Terra, 1986.

SAUL, A. M. Ensinar-aprender: a inspiração de Paulo Freire para a prática docente. In: BRITO, R.L.G. L. de; SAUL, A. M. ; ALVES, D. R. M. Paulo Freire: contribuições para o ensino, a pesquisa e a gestão da educação. Prefácio de Eliete Santiago. Rio de janeiro: Letra capital, 2014. p. 29-51

SAUL, A. M.: SAUL, A. Uma trama conceitual centrada no currículo inspirada na Pedagogia do Oprimido. São Paulo: Revista e-Curriculum, v.16, n.4, p.1.142-1.174, 2018. Doi:

10.23925/1809-3876.2018v16i4p1142-1174. Disponível em:

https://revistas.pucsp.br/index.php/curriculum/article/view/39550. Acesso em: 18 abr. 2020.

Submetido em 12 de maio de 2020.

Aprovado em 14 de outubro de 2020. 